\title{
Transient Analysis of a Tandem Communication Network with Dynamic Bandwidth Allocation having Two Stage Direct Bulk Arrivals
}

\author{
Kuda Nageswara Rao \\ Dept. of CS \& SE, AUCE \\ Andhra University \\ Visakhapatnam, INDIA
}

\author{
K.Srinivas rao \\ Dept. of Statistics \\ Andhra University \\ Visakhapatnam, INDIA
}

\author{
P.Srinivasa Rao \\ Dept. of CS \& SE, AUCE \\ Andhra University \\ Visakhapatnam, INDIA
}

\begin{abstract}
Communication network models play a dominant role in optimal utilization of resources. The need for congestion control and to improve quality of service, it is needed to design new communication networks. With this motivation, a two node communication network with dynamic bandwidth allocation (DBA) having two stage bulk arrivals (BA) is introduced and analyzed. The statistical multiplexing of the communication network is developed by characterizing the arrival of packets with compound Poisson process and the transmission completions with Poisson processes. To avoid burstness in buffers, the dynamic bandwidth allocation is adapted utilizing the idle bandwidth in the transmitter depending on content of the buffer. The network performance is evaluated by deriving the performance measures like mean content of the buffers, mean delays in transmitters, throughput of the nodes, utilization of the nodes etc,. The transient analysis of the model reveals that the time has a significant influence on predicting the performance measures of the communication networks. The sensitivity analysis of the model provides evidence that the dynamic bandwidth allocation strategy along with bulk arrival consideration can provide the performance of the network more close to the reality and avoid burstness in buffers. This communication network is much useful for Satellite and Mobile communication, Computer communication etc. This communication network model also includes several of the earlier communication network models as particular cases for specific values of the model parameters.
\end{abstract}

Keywords: Communication Networks, Dynamic Bandwidth Allocation, Two Stage Bulk Arrivals, Performance Evaluation

\section{INTRODUCTION}

Several authors have studied the communication networks as a tandem queue. They have considered that the independence assumption among the underlined service and arrival process (Kleinrock, (1976), Yukuo Hyashida, (1993)). However, in some communication systems like store and forward communication networks, the standard type of independence assumption is realistically inappropriate due to the fact that messages generally preserve their length as they traverse the network. The inter arrival and service sequence at queues internal to the system are thus dependent as they are the queuing processes at each of the nodes of the network through which the same messages are routed. These dependencies can have marked effect on system performance and must be accounted for any realistic analysis. (Anyne Chen et al (2010), Parthasarathy and Selvaraju (2001),
Marcel et al. (2005), Emre and Ezhan (2008), Durresi et al. (2006), Hooi Miin Soo et al. (2003), Stanislav et al. (2009)).

Many of the communication networks which supports Teleprocessing applications are mixed with statistical multiplexing and dynamic engineering skills (Gaujal and Hyon, 2002). To reduce the congestion in buffers, the statistical multiplexing with load dependent strategy has been evolved through bit-dropping and flow control techniques (Sriram et al, (1989), Kin (2002)). However, in bit-dropping and flow control methodologies the focus is on controlling arrival of packets by dropping the least significant bits. The extent of degradation of service quality is a function of the fraction of voice/data cells lost. To have an efficient transmission with high quality, it is needed to consider the variation of transmission rates based on content of the buffer. This type of adjusting the transmission rates depending upon the content of the buffer is known as dynamic bandwidth allocation (DBA).

Limited work has been reported regarding communication networks with dynamic bandwidth allocation except the works of P.S.Varma et al (2007), who have studied the communication network model with the assumption that the transmission rate of packet is adjusted instantaneously depending upon the content of the buffer. However, they assumed that the packet arrival to the buffers connected to the transmitters are in single and follows Poisson process. But, in store and forward communication networks the messages arrived at the source are converted into a random number of packets depending upon the size of the message. As a result of it, the arrival of packets to the buffers is in bulk and the arrival process can be characterized with compound Poisson process. The compound Poisson process is capable of portraying the statistical nature of the bulk arrival of packets to the buffers and analyzes the communication systems more close to the reality. The compound Poisson process also includes the Poisson process as a particular case. With this motivation, Kuda.Nageswara Rao et al (2010), have developed a two node communication network model with dynamic bandwidth allocation having bulk arrivals and they demonstrated that the bulk arrival with dynamic bandwidth allocation consideration reduce the burstness in buffers and improves quality of service (QoS). They consider that the message arrivals are allowed and stored through packetization in the buffer connected to the initial node only. However, in Satellite and Telecommunications, there is a direct arrival of messages (which are converted into packets) to the buffer connected to the second node along with first node arrival. The direct arrival to the second node can reduce the delay in transmission and avoid unnecessary congestion in the first 
buffer since the packets which require only the second transmitter service can be avoided to the first node transmission. Hence, in this paper, we developed and analyzed a communication network model with dynamic bandwidth allocation having direct bulk arrivals to two nodes connected in tandem. This communication network model is capable of predicting the performance measures of several communication systems close to the reality under transient conditions.

Using the transition probability equations, the joint probability generating function of the number of packets in each buffer at a given time' $t$ ' is derived. The network performance measures like, the average content of the buffers, mean delays in transmitters, throughput of the transmitters, idleness of the transmitters are derived explicitly. The effect of the change in input parameters on performance measures is carried through numerical studies.

\section{COMMUNICATION NETWORK MODEL AND TRANISIENT SOLUTION}

Consider a communication network model with two nodes in tandem having bulk arrivals and dynamic bandwidth allocation. The arrivals to node 1 and node 2 are assumed to follow a compound Poisson process with parameters $\lambda_{1}$ and $\lambda_{2}$ respectively. The compound Poisson process is capable of portraying the bulk arrival nature of the communication network. Here, it is considered that the messages that arrive to both nodes are converted into random number of packets and form a batch. The batch size distribution of packets are assumed to follow rectangle ( uniform) distribution probability distribution functions $\mathrm{C}_{\mathrm{k} 1}$ and $\mathrm{C}_{\mathrm{k} 2}$ with parameters $\left(\mathrm{a}_{1}, \mathrm{~b}_{1}\right)$ and $\left(\mathrm{a}_{2}, \mathrm{~b}_{2}\right)$ respectively for buffer 1 and buffer 2 .

It is also assumed that the number of transmissions at each transmitter follow Poisson processes with parameters $\mu_{1}$ and $\mu_{2}$ respectively. The transmission rates of packets in each node are instantaneously adjusted depending on the content of the buffers just before its transmission. The queue discipline is First-In-FirstOut (FIFO). There is no termination of packets after the transmission of first node. The schematic diagram representing the communication network is shown in Figure 1.

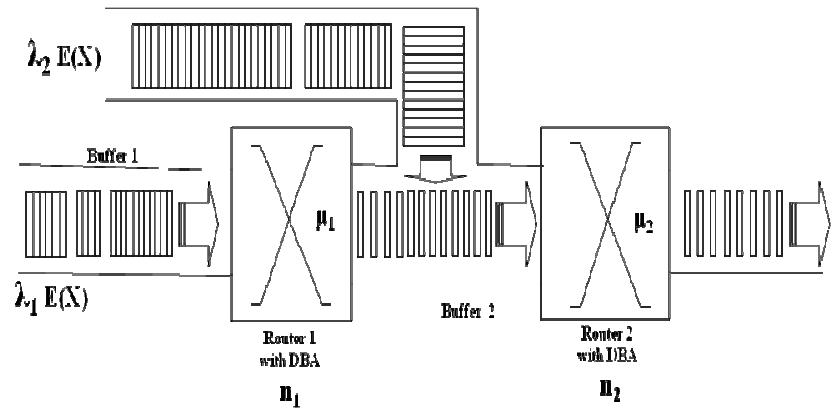

Figure 1. Communication network with two stage Bulk arrivals and dynamic bandwidth allocation

Let $P_{n_{1}, n_{2}}(t)$ be the probability that there are $\mathbf{n}_{\mathbf{1}}$ packets in the first buffer and $\mathbf{n}_{\mathbf{2}}$ packets in the second buffer at time $t$. Then, the difference-differential equations governing the network are

$$
\begin{aligned}
& \frac{\partial \mathrm{P}_{\mathrm{n}_{1}, \mathrm{n}_{2}}(\mathrm{t})}{\partial \mathrm{t}}=-\left(\lambda_{1}+\mathrm{n}_{1} \mu_{1}+\mathrm{n}_{2} \mu_{2}+\lambda_{2}\right) \mathrm{P}_{\mathrm{n}_{1}, \mathrm{n}_{2}}(\mathrm{t})+\left(\mathrm{n}_{1}+1\right) \mu_{1} \mathrm{P}_{\mathrm{n}_{1}+1, \mathrm{n}_{2}-1}(\mathrm{t}) \\
& +\left(\mathrm{n}_{2}+1\right) \mu_{2} \mathrm{P}_{\mathrm{n}_{1}, \mathrm{n}_{2}+1}(\mathrm{t})+\lambda_{1}\left[\sum_{\mathrm{i}=1}^{\mathrm{n}_{1}} \mathrm{P}_{\mathrm{n}_{1}-\mathrm{i}, \mathrm{n}_{2}}(\mathrm{t}) \mathrm{C}_{\mathrm{i} 1}\right]+\lambda_{2}\left[\sum_{\mathrm{j}=1}^{\mathrm{n}_{2}} \mathrm{P}_{\mathrm{n}_{1}, \mathrm{n}_{2}-\mathrm{j}}(\mathrm{t}) \mathrm{C}_{\mathrm{j} 2}\right] \\
& \frac{\partial \mathrm{P}_{\mathrm{n}_{1}, 0}(\mathrm{t})}{\partial \mathrm{t}}=-\left(\lambda_{1}+\mathrm{n}_{1} \mu_{1}+\lambda_{2}\right) \mathrm{P}_{\mathrm{n}_{1}, 0}(\mathrm{t})++\mu_{2} \mathrm{P}_{\mathrm{n}_{1}, 1}(\mathrm{t})+\lambda_{1}\left[\sum_{\mathrm{i}=1}^{\mathrm{n}_{1}} \mathrm{P}_{\mathrm{n}_{1}-\mathrm{i}, 0}(\mathrm{t}) \mathrm{C}_{\mathrm{i} 1}\right] \\
& \frac{\partial \mathrm{P}_{0, \mathrm{n}_{2}}(\mathrm{t})}{\partial \mathrm{t}}=-\left(\lambda_{1}+\mathrm{n}_{2} \mu_{2}+\lambda_{2}\right) \mathrm{P}_{0, \mathrm{n}_{2}}(\mathrm{t})+\mu_{1} \mathrm{P}_{1, \mathrm{n}_{2}-1}(\mathrm{t})+\left(\mathrm{n}_{2}+1\right) \mu_{2} \mathrm{P}_{0, \mathrm{n}_{2}+1}(\mathrm{t})+\lambda_{2}\left[\sum_{j=1}^{\mathrm{n}_{2}} \mathrm{P}_{0, \mathrm{n}_{2}-\mathrm{j}}(\mathrm{t}) \mathrm{C}_{\mathrm{j} 2}\right] \\
& \frac{\partial \mathrm{P}_{1,0}(\mathrm{t})}{\partial \mathrm{t}}=-\left[\lambda_{1}+\mu_{1}+\lambda_{2}\right] \mathrm{P}_{1,0}(\mathrm{t})+\mu_{2} \mathrm{P}_{1,1}(\mathrm{t})+\lambda_{1}\left[\mathrm{P}_{0,0}(\mathrm{t}) \mathrm{C}_{1}\right] \\
& \frac{\partial \mathrm{P}_{0,1}(\mathrm{t})}{\partial \mathrm{t}}=-\left(\lambda_{1}+\mu_{2}+\lambda_{2}\right) \mathrm{P}_{0,1}(\mathrm{t})+\mu_{1} \mathrm{P}_{1,0}(\mathrm{t})+2 \mu_{2} \mathrm{P}_{0,2}(\mathrm{t})+\lambda_{2}\left[\mathrm{P}_{0,0}(\mathrm{t}) \mathrm{C}_{12}\right] \\
& \frac{\partial \mathrm{P}}{\partial \mathrm{t}}(\mathrm{t})
\end{aligned}
$$

with initial conditions

$$
P_{00}(0)=1 ; P_{i, j}(0)=0 \text { for } i, j>0
$$

Let $\mathrm{P}\left(\mathrm{Z}_{1}, \mathrm{Z}_{2}, \mathrm{t}\right)$ be the joint probability generating function of $\mathrm{P}_{\mathrm{n}_{1}, \mathrm{n}_{2}}(\mathrm{t})$ and $\mathrm{C}_{\mathrm{i}}(\mathrm{Z})$ is the probability generating function of \{ $\left.\mathrm{C}_{\mathrm{k}}\right\}$. Then

$P\left(Z_{1}, Z_{2}, t\right)=\sum_{n_{1}=0}^{\infty} \sum_{n_{2}=0}^{\infty} Z_{1}^{n_{1}} Z_{2}^{n_{2}} P_{n_{1}, n_{2}}(t) \quad$ and $C_{i}(Z)=\sum_{k=1}^{\infty} C_{i} Z^{k}$ for $\mathrm{i}=1,2 \ldots$

Multiplying the equations (5.2.1) to (5.2.6) with corresponding $\mathrm{Z}_{1}^{\mathrm{n}_{1}}, \mathrm{Z}_{2}^{\mathrm{n}_{2}}$ and summing

over all $\mathrm{n}_{1}=0,1,2,3, \ldots$, and $\mathrm{n}_{2}=0,1,2,3, \ldots$, one can get

$$
\begin{aligned}
\sum_{n_{1}=0 n_{2}=0}^{\infty} \sum_{0}^{\infty} \frac{\partial}{\partial} P_{n_{1}, n_{2}}(t) Z_{1}^{n_{1}} Z_{2}^{n_{2}}= & -\left[\sum_{n_{1}=0 n_{2}=0}^{\infty} \sum_{1}^{\infty} Z_{1}^{n_{1}} Z_{2}^{n_{2}}\left(n_{1} \mu_{1}+n_{2} \mu_{2}+\lambda_{2}\right) P_{n_{1}, n_{2}}(t)\right] \\
& +\sum_{n_{1}=0 n_{2}=1}^{\infty} \sum^{\infty}\left(n_{1}+1\right) \mu_{1} Z_{1}^{n_{1}} Z_{2}^{n_{2}} P_{n_{1}+1, n_{2}-1}(t)+\sum_{n_{1}=0 n_{2}=0}^{\infty} \sum^{\infty}\left(n_{2}+1\right) \mu_{2} Z_{1}^{n_{1}} Z_{2}^{n_{2}} P_{n_{1}, n_{2}+1}(t) \\
& +\lambda_{1} \sum_{n_{1}=0 n_{2}=0}^{\infty} \sum_{1}^{\infty} Z_{2}^{n_{1}} Z_{2}^{n_{2}} \cdot\left[\sum_{i=1}^{n_{1}} P_{n_{1}-n_{2}, n_{2}}(t) \cdot C_{1_{1}}\right]+\lambda_{2} \sum_{n_{1}=0 n_{2}=0}^{\infty} \sum^{\infty} Z_{1}^{n_{1}} Z_{2}^{n_{2}} \cdot\left[\sum_{j=1}^{n_{2}} P_{n_{1}, n_{2}-j}(t) \cdot C_{j_{2}}\right]
\end{aligned}
$$

After simplification,

$$
\begin{aligned}
\frac{\partial \mathrm{P}\left(\mathrm{Z}_{1}, \mathrm{Z}_{2}, \mathrm{t}\right)}{\partial \mathrm{t}}=\left[\lambda_{1}\left(\mathrm{C}_{1}\left(\mathrm{Z}_{1}\right)-1\right)+\lambda_{2}\left(\mathrm{C}_{2}\left(\mathrm{Z}_{2}\right)-1\right)\right] \mathrm{P}\left(\mathrm{Z}_{1}, \mathrm{Z}_{2}, \mathrm{t}\right) & +\left[\mu_{1}\left(\mathrm{Z}_{2}-\mathrm{Z}_{1}\right)\right] \frac{\partial \mathrm{P}\left(\mathrm{Z}_{1}, \mathrm{Z}_{2}, \mathrm{t}\right)}{\partial \mathrm{Z}_{1}} \\
& +\left[\mu_{2}\left(1-\mathrm{Z}_{2}\right)\right] \frac{\partial \mathrm{P}\left(\mathrm{Z}_{1}, \mathrm{Z}_{2}, \mathrm{t}\right)}{\partial \mathrm{Z}_{2}}
\end{aligned}
$$

Rearranging the terms

$$
\begin{aligned}
& {\left[\lambda_{1}\left(\mathrm{C}_{1}\left(\mathrm{Z}_{1}\right)-1\right)+\lambda_{2}\left(\mathrm{C}_{2}\left(\mathrm{Z}_{2}\right)-1\right)\right] \mathrm{P}\left(\mathrm{Z}_{1}, \mathrm{Z}_{2}, \mathrm{t}\right)} \\
& =\frac{\partial \mathrm{P}\left(\mathrm{Z}_{1}, \mathrm{Z}_{2}, \mathrm{t}\right)}{\partial \mathrm{t}}-\left[\mu_{1}\left(\mathrm{Z}_{2}-\mathrm{Z}_{1}\right)\right] \frac{\partial \mathrm{P}\left(\mathrm{Z}_{1}, \mathrm{Z}_{2}, \mathrm{t}\right)}{\partial \mathrm{Z}_{1}}-\left[\mu_{2}\left(1-\mathrm{Z}_{2}\right)\right] \frac{\partial \mathrm{P}\left(\mathrm{Z}_{1}, \mathrm{Z}_{2}, \mathrm{t}\right)}{\partial \mathrm{Z}_{2}}
\end{aligned}
$$

Using the Lagrangian's method, the auxiliary equations of the equation (9) are

$$
\frac{\mathrm{dt}}{1}=\frac{-\mathrm{dZ}}{\mu_{1}\left(\mathrm{Z}_{2}-\mathrm{Z}_{1}\right)}=\frac{-\mathrm{dZ}}{\mu_{2}\left(1-\mathrm{Z}_{2}\right)}=\frac{\mathrm{dP}\left(\mathrm{Z}_{1}, \mathrm{Z}_{2}, \mathrm{t}\right)}{\left[\lambda_{1}\left(\mathrm{C}_{1}\left(\mathrm{Z}_{1}\right)-1\right)+\lambda_{2}\left(\mathrm{C}_{2}\left(\mathrm{Z}_{2}\right)-1\right)\right] \mathrm{P}\left(\mathrm{Z}_{1}, \mathrm{Z}_{2}, \mathrm{t}\right)}
$$

Solving the equations (5.2.10), one can get 
$\mathrm{u}=\left(\mathrm{Z}_{2}-1\right) \mathrm{e}^{-\mu_{2} \mathrm{t}}$

$\mathrm{v}=\left[\left(Z_{1}-1\right)+\frac{\mu_{1}}{\mu_{2}-\mu_{1}}\left(Z_{2}-1\right)\right] \mathrm{e}^{-\mu_{1} t}$

and

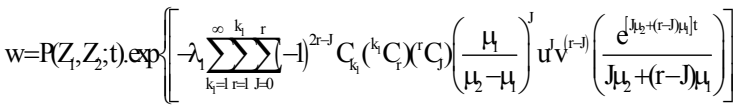

$$
\begin{aligned}
& \left.\left.-\lambda_{2}\left[\sum_{k_{2}=s-1}^{\infty} \sum_{k_{2}}^{k_{2}} C_{2}{ }^{k_{2}} C_{s}\right) u^{s}\left(\frac{e^{\mu-k_{2} t}}{\mu_{2} k_{2}}\right)\right]\right\}
\end{aligned}
$$

where, $\mathbf{u}$ and $\mathbf{v}$ are as given in (11) and (12) respectively, $\mathbf{u}, \mathbf{v}$ and $\mathbf{w}$ are the arbitrary integral constants.

Therefore,

Substituting the value of 'w' and using the initial conditions

$$
\begin{aligned}
\mathrm{P}\left(\mathrm{Z}_{1}, \mathrm{Z}_{2} ; \mathrm{t}\right) & =\exp \left\{\left[\lambda_{1} \sum_{\mathrm{k}_{1}=1}^{\infty} \sum_{\mathrm{r}=1}^{\mathrm{k}_{1}} \sum_{\mathrm{J}=0}^{\mathrm{r}}(-1)^{2 \mathrm{r}-\mathrm{J}} \mathrm{C}_{\mathrm{k}_{1}}{ }^{\mathrm{k}_{1}} \mathrm{C}_{\mathrm{r}}\right)\left({ }^{\mathrm{T}} \mathrm{C}_{\mathrm{J}}\right)\left(\frac{\mu_{1}}{\mu_{2}-\mu_{1}}\right)^{\mathrm{J}} \mathrm{u}^{\mathrm{J}} \mathrm{v}^{(\mathrm{r}-\mathrm{J})}\left(\frac{\mathrm{e}^{\left.\mathrm{J} \mu_{2}+(\mathrm{r}-\mathrm{J}) \mu_{3}\right] \mathrm{t}}-1}{\mathrm{~J} \mu_{2}+(\mathrm{r}-\mathrm{J}) \mu_{1}}\right)\right] \\
& \left.+\lambda_{2}\left[\sum_{\mathrm{k}_{2}=1}^{\infty} \sum_{\mathrm{s}=1}^{\mathrm{k}_{2}} \mathrm{C}_{\mathrm{k}_{2}}\left({ }^{\mathrm{k}_{2}} \mathrm{C}_{\mathrm{s}}\right) \mathrm{u}^{\mathrm{s}}\left(\frac{\mathrm{e}^{\mathrm{u} \mathrm{k}_{2} \mathrm{t}}-1}{\mu_{2} \mathrm{k}_{2}}\right)\right]\right\}
\end{aligned}
$$

Substituting the values of $\mathbf{u}$ and $\mathbf{v}$ in the above equation and simplifying, one can get the joint probability generating function of the number of packets in first buffer and second buffer as

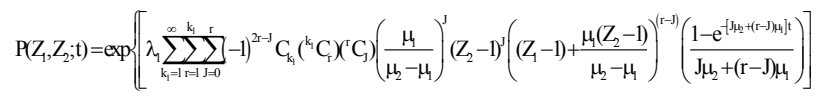

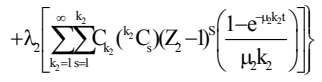

\section{PERFORMANCE MEASURES OF THE NETWORK}

The probability generating function of the first buffer size distribution is

$$
\mathrm{P}\left(\mathrm{Z}_{1}, \mathrm{t}\right)=\exp \left[\lambda_{1} \sum_{\mathrm{k}_{1}=1}^{\infty} \sum_{\mathrm{r}=1}^{\mathrm{k}_{1}}(-1)^{2 \mathrm{r}} \mathrm{C}_{\mathrm{k}_{1}}{ }^{\mathrm{k}_{1}} \mathrm{C}_{\mathrm{r}}\left(\mathrm{Z}_{1}-1\right)^{\mathrm{r}} \frac{\left(1-\mathrm{e}^{-\mathrm{r} \mu_{1} \mathrm{t}}\right)}{\mathrm{r} \mu_{1}}\right]
$$

The probability that the first buffer is empty as

$$
\mathrm{p}_{0 .}(\mathrm{t})=\exp \left[\lambda_{1} \sum_{\mathrm{k}_{1}=1}^{\infty} \sum_{\mathrm{r}=1}^{\mathrm{k}_{1}} \mathrm{C}_{\mathrm{k}_{1}}{ }^{\mathrm{k}_{1}} \mathrm{C}_{\mathrm{r}}(-1)^{3 \mathrm{r}} \frac{\left(1-\mathrm{e}^{-\mathrm{r} \mu_{1} \mathrm{t}}\right)}{\mathrm{r} \mu_{1}}\right]
$$

The utilization of the first node is

$$
\begin{aligned}
& \mathrm{U}_{1}=1-\mathrm{p}_{0 .}(\mathrm{t}) \\
& =1-\exp \left[\lambda_{1} \sum_{\mathrm{k}_{1}=1}^{\infty} \sum_{\mathrm{r}=1}^{\mathrm{k}_{1}} \mathrm{C}_{\mathrm{k}_{1}}{ }^{\mathrm{k}_{1}} \mathrm{C}_{\mathrm{r}}(-1)^{3 \mathrm{r}} \frac{\left(1-\mathrm{e}^{-\mathrm{r} \mu_{1} \mathrm{t}}\right)}{\mathrm{r} \mu_{1}}\right]
\end{aligned}
$$

The mean number of packets in the first buffer is

$$
\mathrm{L}_{1}=\frac{\lambda_{1}}{\mu_{1}}\left[\sum_{\mathrm{k}_{1}=1}^{\infty} \mathrm{C}_{\mathrm{k}_{1}} \cdot \mathrm{k}_{1}\left(1-\mathrm{e}^{-\mu_{1} \mathrm{t}}\right)\right]
$$

Throughput of the first node is

$$
\begin{aligned}
& \operatorname{Thp}_{1}=\mu_{1} \cdot \mathrm{U}_{1} \\
& =\mu_{1}\left[1-\exp \left[\lambda_{1} \sum_{\mathrm{k}_{1}=1}^{\infty} \sum_{\mathrm{r}=1}^{\mathrm{k}_{1}} \mathrm{C}_{\mathrm{k}_{1}}{ }^{\mathrm{k}_{1}} \mathrm{C}_{\mathrm{r}}(-1)^{3 \mathrm{r}} \frac{\left(1-\mathrm{e}^{-\mathrm{r} \mu_{1} \mathrm{t}}\right)}{\mathrm{r} \mu_{1}}\right]\right]
\end{aligned}
$$

The average delay in the first buffer is

$$
\mathrm{W}\left(\mathrm{N}_{1}\right)=\frac{\mathrm{L}_{1}}{\mathrm{Thp}_{1}}=\frac{\frac{\lambda_{1}}{\mu_{1}}\left[\sum_{\mathrm{k}_{1}=1}^{\infty} \mathrm{C}_{\mathrm{k}_{1}} \cdot \mathrm{k}_{1}\left(1-\mathrm{e}^{-\mu_{1} \mathrm{t}}\right)\right]}{=\mu_{1}\left[1-\exp \left[\lambda_{1} \sum_{\mathrm{k}_{1}=1}^{\infty} \sum_{\mathrm{r}=1}^{\mathrm{k}_{1}} \mathrm{C}_{\mathrm{k}_{1}}{ }^{\mathrm{k}_{1}} \mathrm{C}_{\mathrm{r}}(-1)^{3 \mathrm{r}} \frac{\left(1-\mathrm{e}^{-\mathrm{r} \mu_{1} \mathrm{t}}\right)}{\mathrm{r} \mu_{1}}\right]\right]}
$$

The variance of the number of packets in the first buffer is

$$
\begin{aligned}
& \operatorname{Var}\left(\mathrm{N}_{1}\right)=\mathrm{E}\left[\mathrm{N}_{1}^{2}-\mathrm{N}_{1}\right]+\mathrm{E}\left[\mathrm{N}_{1}\right]-\left(\mathrm{E}\left[\mathrm{N}_{1}\right]\right)^{2} \\
& =\frac{\lambda_{1}}{2 \mu_{1}}\left[\sum_{\mathrm{k}_{1}=1}^{\infty} \mathrm{C}_{\mathrm{k}_{1}} \mathrm{k}_{1}\left(\mathrm{k}_{1}-1\right)\left(1-\mathrm{e}^{-2 \mu_{1} \mathrm{t}}\right)\right]+\frac{\lambda_{1}}{\mu_{1}}\left[\sum_{\mathrm{k}_{1}=1}^{\infty} \mathrm{C}_{\mathrm{k}_{1}} \mathrm{k}_{1}\left(1-\mathrm{e}^{-\mu_{1} \mathrm{t}}\right)\right]
\end{aligned}
$$

The coefficient of variation of the number of packets in the first buffer is

$\operatorname{cv}\left(\mathrm{N}_{1}\right)=\frac{\sqrt{\mathrm{Var}\left(\mathrm{N}_{1}\right)}}{\mathrm{L}_{1}}$

The probability generating function of the second buffer size distribution is

$$
\begin{array}{r}
\mathrm{P}\left(\mathrm{Z}_{2}, \mathrm{t}\right)=\exp \left\{\left[\lambda_{1} \sum_{\mathrm{k}_{1}=1}^{\infty} \sum_{\mathrm{r}=1}^{\mathrm{k}_{1}} \sum_{\mathrm{J}=0}^{\mathrm{r}}(-1)^{2 \mathrm{r}-\mathrm{J}} \mathrm{C}_{\mathrm{k}_{1}}\left({ }^{\mathrm{k}_{1}} \mathrm{C}_{\mathrm{r}}\right)\left(\mathrm{r}_{\mathrm{J}}\right)\left(\frac{\mu_{1}}{\mu_{2}-\mu_{1}}\right)^{\mathrm{r}}\left(\mathrm{Z}_{2}-1\right)^{\mathrm{r}}\left(\frac{1-\mathrm{e}^{-\left[\mathrm{J} \mu_{2}+\left(\mathrm{r}-\mathrm{r}-\mu_{\mathrm{H}}\right] \mathrm{t}\right.}}{\mathrm{J} \mu_{2}+(\mathrm{r}-\mathrm{J}) \mu_{1}}\right)\right]\right. \\
\left.\left.+\lambda_{2}\left[\sum_{\mathrm{k}_{2}=1}^{\infty} \sum_{\mathrm{s}=1}^{\mathrm{k}_{2}} \mathrm{C}_{\mathrm{k}_{2}}{ }^{\mathrm{k}_{2}} \mathrm{C}_{\mathrm{s}}\right)\left(\mathrm{Z}_{2}-1\right)^{\mathrm{s}}\left(\frac{1-\mathrm{e}^{-\mu_{2} \mathrm{k}_{2} \mathrm{t}}}{\mu_{2} \mathrm{k}_{2}}\right)\right]\right\}
\end{array}
$$

The probability that the second buffer is empty as

$$
\begin{array}{r}
\mathrm{p}_{.0}(\mathrm{t})=\exp \left\{\left[\lambda_{1} \sum_{\mathrm{k}_{1}=1}^{\infty} \sum_{\mathrm{r}=1}^{\mathrm{k}_{1}} \sum_{\mathrm{J}=0}^{\mathrm{r}}(-1)^{3 \mathrm{r}-\mathrm{J}} \mathrm{C}_{\mathrm{k}_{1}}\left({ }^{\mathrm{k}_{1}} \mathrm{C}_{\mathrm{r}}\right)\left({ }^{\mathrm{r}} \mathrm{C}_{\mathrm{J}}\right)\left(\frac{\mu_{1}}{\mu_{2}-\mu_{1}}\right)^{\mathrm{r}}\left(\frac{1-\mathrm{e}^{-\left[\mathrm{J} \mu_{2}+(\mathrm{r}-\mathrm{J}) \mu_{1}\right] \mathrm{t}}}{\mu_{\mu_{2}}+(\mathrm{r}-\mathrm{J}) \mu_{1}}\right)\right]\right. \\
\left.+\lambda_{2}\left[\sum_{\mathrm{k}_{2}=1}^{\infty} \sum_{\mathrm{s}=1}^{\mathrm{k}_{2}} \mathrm{C}_{\mathrm{k}_{2}}\left({ }^{\mathrm{k}_{2}} \mathrm{C}_{\mathrm{s}}\right)(-1)^{\mathrm{s}}\left(\frac{1-\mathrm{e}^{-\mu_{2} \mathrm{k}_{2} \mathrm{t}}}{\mu_{2} \mathrm{k}_{2}}\right)\right]\right\}
\end{array}
$$

The utilization of the second node is

$$
\begin{aligned}
& \mathrm{U}_{2}=1-\mathrm{p}_{.0}(\mathrm{t}) \\
& =1-\exp \left\{\left[\lambda_{1} \sum_{\mathrm{k}_{1}=1}^{\infty} \sum_{\mathrm{r}=1}^{k_{1}} \sum_{J=0}^{\mathrm{r}}(-1)^{3 \mathrm{r}-\mathrm{J}} \mathrm{C}_{\mathrm{k}_{1}}\left({ }^{\mathrm{k}_{1}} \mathrm{C}_{\mathrm{r}}\right)\left({ }^{\mathrm{r}} \mathrm{C}_{\mathrm{J}}\right)\left(\frac{\mu_{1}}{\mu_{2}-\mu_{1}}\right)^{\mathrm{r}}\left(\frac{1-\mathrm{e}^{-\left[\mathrm{J} \mu_{2}+(\mathrm{r}-\mathrm{J}) \mu_{1}\right] \mathrm{t}}}{\mathrm{J} \mu_{2}+(\mathrm{r}-\mathrm{J}) \mu_{1}}\right)\right]\right. \\
& \left.+\lambda_{2}\left[\sum_{\mathrm{k}_{2}=1}^{\infty} \sum_{\mathrm{s}=1}^{k_{2}} \mathrm{C}_{\mathrm{k}_{2}}\left({ }^{\mathrm{k}_{2}} \mathrm{C}_{\mathrm{s}}\right)(-1)^{\mathrm{s}}\left(\frac{1-\mathrm{e}^{-\mu_{2} k_{2} t}}{\mu_{2} \mathrm{k}_{2}}\right)\right]\right\}
\end{aligned}
$$

The mean number of packets in the second buffer is

$\mathrm{L}_{2}=\frac{\lambda_{1}}{\mu_{2}}\left(\sum_{\mathrm{k}_{1}=}^{\infty} \mathrm{C}_{\mathrm{k}_{1}} \mathrm{k}_{1}\right)\left[\left(1-\mathrm{e}^{-\mu_{2} \mathrm{t}}\right)+\frac{\mu_{2}}{\mu_{2}-\mu_{1}}\left(\mathrm{e}^{-\mu_{2} \mathrm{t}}-\mathrm{e}^{-\mu_{1} \mathrm{t}}\right)\right]+\frac{\lambda_{2}}{\mu_{2}}\left(\sum_{\mathrm{k}_{2}=1}^{\infty} \mathrm{C}_{\mathrm{k}_{2}} \mathrm{k}_{2}\right)\left(1-\mathrm{e}^{-\mu_{2} \mathrm{t}}\right)$

Throughput of the second node is 


$$
\begin{aligned}
& \mathrm{Thp}_{2}=\mu_{2} \cdot \mathrm{U}_{2}
\end{aligned}
$$

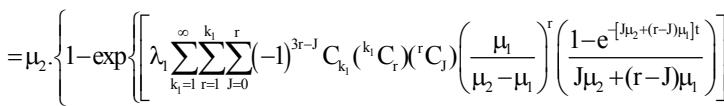

$$
\begin{aligned}
& \left.\left.\left.+\lambda_{2}\left[\sum_{k_{2}=1}^{\infty} \sum_{s=1}^{k_{2}} C_{k_{2}}{ }^{k_{2}} C_{s}\right)(-1)^{s}\left(\frac{1-e^{-\mu k_{2} t}}{\mu_{2} k_{2}}\right)\right]\right\}\right\}
\end{aligned}
$$

The average delay in the second buffer is

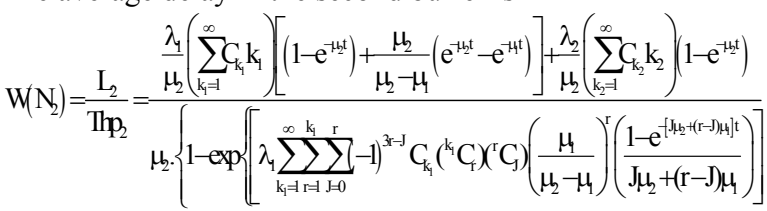

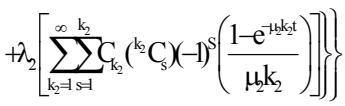

The variance of number of packets in the second buffer is

$$
\begin{aligned}
& \operatorname{Var}\left(\mathrm{N}_{2}\right)=\mathrm{E}\left[\mathrm{N}_{2}^{2}-\mathrm{N}_{2}\right]+\mathrm{E}\left[\mathrm{N}_{2}\right]-\left(\mathrm{E}\left[\mathrm{N}_{2}\right]\right)^{2} \\
& =\lambda_{1}\left\{\left(\sum_{k_{1}=1}^{\infty} C_{k_{1}} k_{1}\left(k_{1}-1\right)\right)\left(\frac{\mu_{1}}{\mu_{1}-\mu_{2}}\right)^{2}\left[\left(\frac{1-e^{-2 \mu_{1} t}}{2 \mu_{1}}\right)-2\left(\frac{1-e^{-\left(\mu_{1}+\mu_{2}\right) t}}{\mu_{1}+\mu_{2}}\right)+\left(\frac{1-e^{-2 \mu_{2} t}}{2 \mu_{2}}\right)\right]\right\}
\end{aligned}
$$

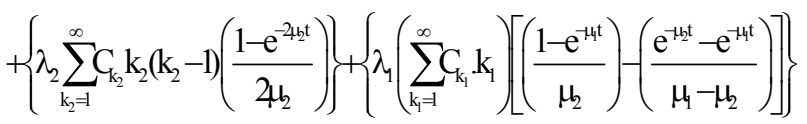

$$
\begin{aligned}
& +\left\{\frac{\lambda_{2}}{\mu_{2}}\left(\sum_{k_{2}=1}^{\infty} \mathrm{C}_{k_{2}} \cdot \mathrm{k}_{2}\right)\left(1-\mathrm{e}^{\left.-\mu_{2} \mathrm{t}\right)}\right\}\right.
\end{aligned}
$$

The coefficient of variation of the number of packets in the second buffer is

$\operatorname{cv}\left(\mathrm{N}_{2}\right)=\frac{\sqrt{\mathrm{Var}\left(\mathrm{N}_{2}\right)}}{\mathrm{L}_{2}}$

The probability that the network is empty as

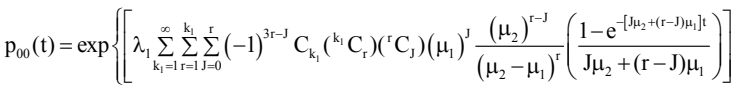

$$
\begin{aligned}
& \left.+\lambda_{2}\left[\sum_{k_{2}=1}^{\infty} \sum_{s=1}^{k_{2}} \mathrm{C}_{k_{2}}\left(k_{2} \mathrm{C}_{\mathrm{s}}\right)(-1)^{\mathrm{s}}\left(\frac{1-\mathrm{e}^{-\mu_{2} \mathrm{~s}} \mathrm{t}}{\mu_{2} \mathrm{~S}}\right)\right]\right\}
\end{aligned}
$$

The mean number of packets in the network is

$\mathrm{L}_{\mathrm{N}}=\mathrm{L}_{1}+\mathrm{L}_{2}$

\section{PARTICULAR CASE WHEN THE BATCH SIZE IS UNIFORMLY DISTRIBUTED}

The performance of the communication network is highly influenced by the structure of batch size distribution. In most of the communication systems the number of packets that a message can be converted is random and follows a uniform (rectangular) distribution with parameters $a$ and $b$.

The probability mass function of the number of packets in a message at the first node is

$C_{k_{1}}=\left(\frac{1}{b_{1}-a_{1}+1}\right)$ for $k_{1}=a_{1}, a_{1}+1, \ldots, b_{1}$.

The mean number of packets in a message is $\left(\frac{a_{1}+b_{1}}{2}\right)$

and its variance is $\frac{1}{12}\left[\left(b_{1}-a_{1}+1\right)^{2}-1\right]$.

The probability mass function of the number of packets in a message at the second node is $\mathrm{C}_{\mathrm{k}_{2}}=\left(\frac{1}{\mathrm{~b}_{2}-\mathrm{a}_{2}+1}\right)$ for $\mathrm{k}_{2}=\mathrm{a}_{2}$, $a_{2}+1, \ldots, b_{2}$.

The mean number of packets in a message is $\left(\frac{a_{2}+b_{2}}{2}\right)$

and its variance is $\frac{1}{12}\left[\left(b_{2}-a_{2}+1\right)^{2}-1\right]$.

Substituting the value of $\mathrm{C}_{\mathrm{k}_{1}}$ and $\mathrm{C}_{\mathrm{k}_{2}}$ in (1), one can get the joint probability generating function of the number of packets in both the buffers as

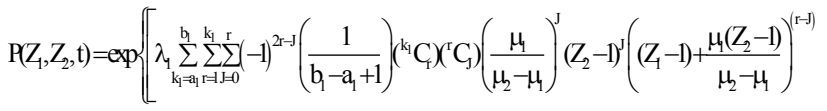

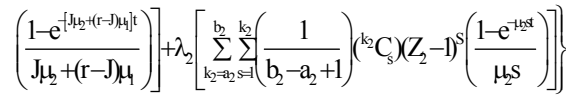

The probability generating function of the first buffer size distribution is

$\mathrm{P}\left(\mathrm{Z}_{1}, \mathrm{t}\right)=\exp \left[\lambda_{1} \sum_{\mathrm{k}_{1}=\mathrm{a}_{1}}^{\mathrm{b}_{2}} \sum_{\mathrm{r}=1}^{\mathrm{k}_{1}}(-1)^{2 \mathrm{r}}\left(\frac{1}{\mathrm{~b}_{1}-\mathrm{a}_{1}+1}\right) \mathrm{k}^{\mathrm{k}_{1}} \mathrm{C}_{\mathrm{r}}\left(\mathrm{Z}_{1}-1\right)^{\mathrm{r}} \frac{\left(1-\mathrm{e}^{-\mathrm{r} \mu_{1} \mathrm{t}}\right)}{\mathrm{r} \mu_{1}}\right]$

The probability that the first buffer is empty as

$\mathrm{p}_{0 .}(\mathrm{t})=\exp \left[\lambda_{1} \sum_{\mathrm{k}_{1}=\mathrm{a}_{1}}^{\mathrm{b}_{1}} \sum_{\mathrm{r}=1}^{\mathrm{k}_{1}}\left(\frac{1}{\mathrm{~b}_{1}-\mathrm{a}_{1}+1}\right) \mathrm{k}^{\mathrm{k}_{1}} \mathrm{C}_{\mathrm{r}}(-1)^{3 \mathrm{r}} \frac{\left(1-\mathrm{e}^{-\mathrm{r} \mu_{1} \mathrm{t}}\right)}{\mathrm{r} \mu_{1}}\right]$

The mean number of packets in the first buffer is

$\mathrm{L}_{1}=\frac{\lambda_{1}\left(\mathrm{a}_{1}+\mathrm{b}_{1}\right)}{2 \mu_{1}}\left(1-\mathrm{e}^{-\mu_{1} \mathrm{t}}\right)$

The utilization of the first node is

$\mathrm{U}_{1}=1-\mathrm{p}_{0 .}(\mathrm{t})$ 


$$
=1-\exp \left[\lambda_{1} \sum_{\mathrm{k}_{1}=\mathrm{a}_{1}}^{\mathrm{b}_{1}} \sum_{\mathrm{r}=1}^{\mathrm{k}_{1}}\left(\frac{1}{\mathrm{~b}_{1}-\mathrm{a}_{1}+1}\right) \mathrm{k}_{\mathrm{r}} \mathrm{C}_{\mathrm{r}}(-1)^{3 \mathrm{r}} \frac{\left(1-\mathrm{e}^{-\mathrm{r} \mu_{1} \mathrm{t}}\right)}{\mathrm{r} \mu_{1}}\right]
$$

The throughput of the first node is

$$
\begin{aligned}
& \operatorname{Thp}_{1}=\mu_{1} \cdot U_{1} \\
& =\mu_{1}\left\{1-\exp \left[\lambda_{1} \sum_{k_{1}=a_{1}}^{b_{1}} \sum_{=1}^{k_{1}}\left(\frac{1}{b_{1}-a_{1}+1}\right){ }^{k_{1}} C_{r}(-1)^{3 r} \frac{\left(1-e^{-r \mu_{1} t}\right)}{r \mu_{1}}\right]\right\}
\end{aligned}
$$

The average delay in the first buffer is

$$
\mathrm{W}\left(\mathrm{N}_{\mathrm{l}}\right)=\frac{\mathrm{L}_{1}}{\operatorname{Th} p_{1}}=\frac{\frac{\lambda_{1}\left(\mathrm{a}_{1}+\mathrm{b}_{1}\right)}{2 \mu_{1}}\left(1-\mathrm{e}^{-\mu_{t} t}\right)}{\mu_{1}\left\{1-\exp \left[\lambda_{1} \sum_{\mathrm{k}_{1}=\mathrm{a}_{1}=1}^{b_{1}=1} \sum_{1}^{k_{1}}\left(\frac{1}{b_{1}-\mathrm{a}_{1}+1}\right)^{k_{1}} \mathrm{C}_{\mathrm{r}}(-1)^{3 \mathrm{r}} \frac{\left(1-\mathrm{e}^{-\mu_{\mathrm{t}} t}\right)}{\mathrm{r} \mu_{1}}\right]\right\}}
$$

The variance of the number of packets in the first buffer is $\operatorname{Var}\left(\mathrm{N}_{1}\right)=\mathrm{E}\left[\mathrm{N}_{1}^{2}-\mathrm{N}_{1}\right]+\mathrm{E}\left[\mathrm{N}_{1}\right]-\left(\mathrm{E}\left[\mathrm{N}_{1}\right]\right)^{2}$

$=\frac{\lambda_{1}}{2 \mu_{1}}\left[\sum_{k_{1}=a_{1}}^{b_{1}}\left(\frac{1}{b_{1}-a_{1}+1}\right) k_{1}\left(k_{1}-1\right)\left(1-e^{-2 \mu l t}\right)\right]+\frac{\lambda_{1}}{\mu_{1}}\left[\sum_{k_{1}=a_{1}}^{b_{1}}\left(\frac{1}{b_{1}-a_{1}+1}\right) k_{1}\left(1-e^{-\mu_{t} t}\right)\right]$

The coefficient of variation of the number of packets in the first buffer is

$\operatorname{cv}\left(\mathrm{N}_{1}\right)=\frac{\sqrt{\mathrm{V} \operatorname{ar}\left(\mathrm{N}_{1}\right)}}{\mathrm{L}_{1}}$

The probability generating function of the second buffer size distribution as

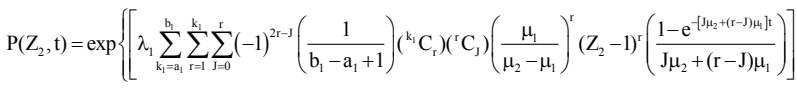

$$
\begin{aligned}
& \left.+\lambda_{2}\left[\sum_{k_{2}=a_{2}}^{b_{2}} \sum_{s=1}^{k_{2}}\left(\frac{1}{b_{2}-a_{2}+1}\right)\left(k^{k_{2}} C_{s}\right)\left(Z_{2}-1\right)^{s}\left(\frac{1-e^{-\mu_{2} s t}}{\mu_{2} s}\right)\right]\right\}
\end{aligned}
$$

The probability that the second buffer is empty as

$$
\begin{aligned}
\mathrm{p}_{0}(\mathrm{t}) & =\exp \left\{\left[\lambda_{1} \sum_{\mathrm{k}_{1}=\mathrm{a}_{1}}^{\mathrm{b}_{1}} \sum_{\mathrm{r}=1}^{k_{1}} \sum_{\mathrm{J}=0}^{\mathrm{r}}(-1)^{3 \mathrm{r}-\mathrm{J}}\left(\frac{1}{\mathrm{~b}_{1}-\mathrm{a}_{1}+1}\right)\left({ }^{\mathrm{k}_{1}} \mathrm{C}_{\mathrm{r}}\right)\left({ }^{\mathrm{r}} \mathrm{C}_{\mathrm{J}}\right)\left(\frac{\mu_{1}}{\mu_{2}-\mu_{1}}\right)^{\mathrm{r}}\left(\frac{1-\mathrm{e}^{-\left[\mu_{2}+(\mathrm{r}-J) \mu_{1}\right] \mathrm{t}}}{\mathrm{J} \mu_{2}+(\mathrm{r}-\mathrm{J}) \mu_{1}}\right)\right]\right. \\
& \left.+\lambda_{2}\left[\sum_{\mathrm{k}_{2}=\mathrm{a}_{2}}^{\mathrm{b}_{2}} \sum_{\mathrm{s}=1}^{\mathrm{k}_{2}}\left(\frac{1}{\mathrm{~b}_{2}-\mathrm{a}_{2}+1}\right)\left({ }^{\mathrm{k}_{2}} \mathrm{C}_{\mathrm{s}}\right)(-1)^{\mathrm{s}}\left(\frac{1-\mathrm{e}^{-\mu_{2} \mathrm{~s} \mathrm{t}}}{\mu_{2} \mathrm{~S}}\right)\right]\right\}
\end{aligned}
$$

The mean number of packets in the second buffer is

$\mathrm{L}_{2}=\frac{\lambda_{1}\left(\mathrm{a}_{1}+\mathrm{b}_{1}\right)}{2 \mu_{2}}\left[\left(1-\mathrm{e}^{-\mu_{2} \mathrm{t}}\right)+\frac{\mu_{2}}{\mu_{2}-\mu_{1}}\left(\mathrm{e}^{-\mu_{2} \mathrm{t}}-\mathrm{e}^{-\mu_{1} \mathrm{t}}\right)\right]+\frac{\lambda_{2}\left(\mathrm{a}_{2}+\mathrm{b}_{2}\right)}{2 \mu_{2}}\left(1-\mathrm{e}^{-\mu_{2} \mathrm{t}}\right)$

The utilization of the second node is

$$
\begin{aligned}
& \mathrm{U}_{2}=1-\mathrm{p}_{.0}(\mathrm{t}) \\
& =1-\exp \left\{\left[\lambda_{1} \sum_{k_{1}=a_{1}}^{b_{1}} \sum_{r=1}^{k_{1}} \sum_{J=0}^{r}(-1)^{3 r-J}\left(\frac{1}{b_{1}-a_{1}+1}\right)\left({ }^{k_{1}} C_{r}\right)\left({ }^{r} C_{J}\right)\left(\frac{\mu_{1}}{\mu_{2}-\mu_{1}}\right)^{r}\left(\frac{1-e^{-\left[J \mu_{2}+(r-J) \mu_{1}\right] t}}{J \mu_{2}+(r-J) \mu_{1}}\right)\right]\right. \\
& \left.+\lambda_{2}\left[\sum_{k_{2}=a_{2}}^{b_{2}} \sum_{s=1}^{k_{2}}\left(\frac{1}{b_{2}-a_{2}+1}\right)\left({ }^{k_{2}} C_{s}\right)(-1)^{s}\left(\frac{1-e^{-\mu_{2} \mathrm{st}}}{\mu_{2} \mathrm{~s}}\right)\right]\right\}
\end{aligned}
$$

The throughput of the second node is

$$
\begin{aligned}
& \mathrm{Thp}_{2}=\mu_{2} \cdot \mathrm{U}_{2}
\end{aligned}
$$

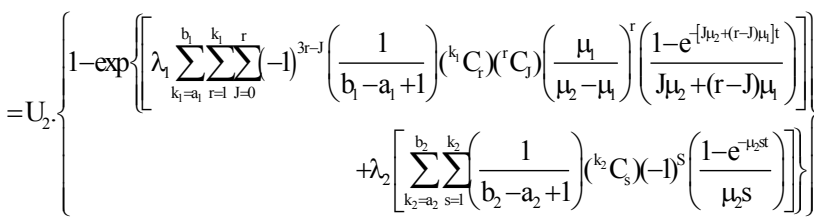

The average delay in the second buffer is

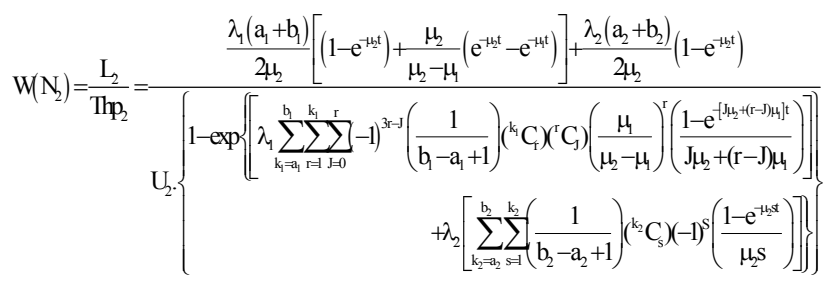

The variance of number of packets in the second buffer is

$$
\begin{aligned}
& \operatorname{Var}\left(\mathrm{N}_{2}\right)=\mathrm{E}\left[\mathrm{N}_{2}^{2}-\mathrm{N}_{2}\right]+\mathrm{E}\left[\mathrm{N}_{2}\right]-\left(\mathrm{E}\left[\mathrm{N}_{2}\right]\right)^{2} \\
& =\lambda_{1}\left\{\left(\sum_{\mathrm{k}_{1}=\mathrm{a}_{1}}^{\mathrm{b}_{1}}\left(\frac{1}{\mathrm{~b}_{1}-\mathrm{a}_{1}+1}\right) \cdot \mathrm{k}_{1}\left(\mathrm{k}_{1}-1\right)\right)\left(\frac{\mu_{1}}{\mu_{1}-\mu_{2}}\right)^{2}\left[\left(\frac{1-\mathrm{e}^{-2 \mu_{1} \mathrm{t}}}{2 \mu_{1}}\right)-2\left(\frac{1-\mathrm{e}^{-\left(\mu_{1}+\mu_{2}\right) \mathrm{t}}}{\mu_{1}+\mu_{2}}\right)+\left(\frac{1-\mathrm{e}^{-2 \mu_{2} t}}{2 \mu_{2}}\right)\right]\right\} \\
& +\left\{\lambda_{2} \sum_{\mathrm{k}_{2}=\mathrm{a}_{2}}^{\mathrm{b}_{2}}\left(\frac{1}{\mathrm{~b}_{2}-\mathrm{a}_{2}+1}\right) \mathrm{k}_{2}\left(\mathrm{k}_{2}-1\right)\left(\frac{1-\mathrm{e}^{-2 \mu_{2} \mathrm{t}}}{2 \mu_{2}}\right)\right\}+\left\{\lambda_{1}\left(\frac{\mathrm{a}_{1}+\mathrm{b}_{1}}{2}\right)\left[\left(\frac{1-\mathrm{e}^{-\mu_{1} \mathrm{t}}}{\mu_{2}}\right)-\left(\frac{\mathrm{e}^{-\mu_{2} \mathrm{t}}-\mathrm{e}^{-\mu_{1} \mathrm{t}}}{\mu_{1}-\mu_{2}}\right)\right]\right\} \\
& +\left\{\frac{\lambda_{2}}{\mu_{2}}\left(\frac{\mathrm{a}_{2}+\mathrm{b}_{2}}{2}\right)\left(1-\mathrm{e}^{-\mu_{2} \mathrm{t}}\right)\right\}
\end{aligned}
$$

The coefficient of variation of the number of packets in the second buffer is

$$
\operatorname{cv}\left(\mathrm{N}_{2}\right)=\frac{\sqrt{\mathrm{V} \operatorname{ar}\left(\mathrm{N}_{2}\right)}}{\mathrm{L}_{2}}
$$

The probability that the network is empty as

$$
\begin{aligned}
p_{00}(t) & =\exp \left\{\left[\lambda_{1} \sum_{k_{1}=a_{1}}^{b_{1}} \sum_{r=1}^{k_{1}} \sum_{j=0}^{r}(-1)^{3 r-j}\left(\frac{1}{b_{1}-a_{1}+1}\right){ }^{k_{1}} C_{r}\right)\left({ }^{r} C_{J}\right)\left(\mu_{1}\right)^{J} \frac{\left[\mu_{2}\right]^{r-j}}{\left(\mu_{2}-\mu_{1}\right)^{r}}\left(\frac{1-e^{-\left[\mu_{\mu_{2}}+(r-J) \mu_{1}\right] t}}{J \mu_{2}+(r-J) \mu_{1}}\right)\right] \\
& \left.+\lambda_{2}\left[\sum_{k_{2}=a_{2}}^{b_{2}} \sum_{s=1}^{k_{2}}\left(\frac{1}{b_{2}-a_{2}+1}\right)\left({ }^{k_{2}} C_{s}\right)(-1)^{s}\left(\frac{1-e^{-\mu_{2} s t}}{\mu_{2} s}\right)\right]\right\}
\end{aligned}
$$

The mean number of packets in the network is

$$
\mathrm{L}_{\mathrm{N}}=\mathrm{L}_{1}+\mathrm{L}_{2}
$$

\section{PERFORMANCE EVALUATION OF THE NETWORK}

The performance of the proposed network is discussed through numerical illustration. Different values of the parameters are considered for bandwidth allocation and arrival of packets. Consider the communication network with two-stage bulk arrivals and dynamic bandwidth allocation (CN TS BA DBA). $\lambda_{1}$ and $\lambda_{2}$ are the arrival rates at node 1 and node 2 respectively. The number of packets that can be converted into a message varies 
from 1 to 10 depending on the length of the message. The number of arrivals of packets to the buffers is in batches of random size. The batch size is assumed to follow uniform (rectangle) distribution with parameters $\left(a_{1}, b_{1}\right)$ and $\left(a_{2}, b_{2}\right)$ for buffer 1 and buffer 2 respectively. The transmission rate of node $1\left(\mu_{1}\right)$ which varies from $10 \times 10^{4}$ packets $/ \mathrm{sec}$ to $14 \times 10^{4}$ packets/sec. The packets leave the second node with a transmission rate of $\mu_{2}$ which varies from $16 \times 10^{4}$ packets $/ \mathrm{sec}$ to $20 \times 10^{4}$ packets/sec. In both the nodes, dynamic bandwidth allocation is considered i.e. the transmission rate of each packet depends on the number of packets in the buffer connected to it at that instant.

Since performance characteristics of the communication network are highly sensitive with respect to time, the transient behavior of the model is studied through computing the performance measures with the following set of values for the model parameters as

$\mathrm{t}=0.05,0.1,0.2,0.3,0.4$ seconds, $\quad \mathrm{a}_{1}=1,2,3,4,5$

$\mathrm{b}_{1}=6,7,8,9,10, \mathrm{a}_{2}=1,2,3,4,5, \quad \mathrm{~b}_{2}=6,7,8,9,10$

$\lambda_{1}=0.5,1.5,2.0,2.5$ (with multiplication of $10^{4}$ messages $/ \mathrm{sec}$ )

$\lambda_{2}=0.5,1.5,2.0,2.5$ (with multiplication of $10^{4}$ messages $/ \mathrm{sec}$ )

$\mu_{1}=10,11,12,13,14$ (with multiplication of $10^{4}$ packets $/ \mathrm{sec}$ )

and $\mu_{2}=16,17,18,19,20$ (with multiplication of $10^{4}$ packets/sec)
Using equations (35), (43) and (50), the probability of network emptiness and buffers emptiness are computed for different values of $t, a_{1}, b_{1}, a_{2}, b_{2}, \lambda_{1}, \lambda_{2}, \mu_{1}, \mu_{2}$ and observed that the probability of emptiness of the communication network and the two buffers are highly sensitive with respect to changes in time. As time $(\mathrm{t})$ varies from 0.1 to 1 second, the probability of emptiness of the network reduces from 0.75747 to 0.60066 and the probability of emptiness of the two buffers reduce from 0.91547 to 0.83043 and 0.79383 to 0.67146 for node 1 and node 2 respectively.

When the batch distribution parameters $a_{1}, b_{1}$ and the message arrival rate $\lambda_{1}$ at node 1 increase, the probability of emptiness of the network and the probabilities of emptiness of the first and second buffers decrease. When the batch distribution parameters $a_{2}, b_{2}$ and the message arrival rate $\lambda_{2}$ at node 2 increase, the probability of emptiness of the network and the probability of emptiness of the second buffer decrease and the probability of emptiness of the first buffer remains unchanged.

It is observed that the probability of emptiness of the network and the probabilities of emptiness of the first and second buffers are increasing when the transmission rate of node $1\left(\mu_{1}\right)$ is increasing. When the transmission rate of node $2\left(\mu_{2}\right)$ increase, the probabilities of emptiness of the network and the second buffer increase and the probability of emptiness of the first buffer remains unchanged.

Table 1. Values of Mean number of packets, Throughput and mean delay

\begin{tabular}{|c|c|c|c|c|c|c|c|c|c|c|c|c|c|c|c|}
\hline$t^{*}$ & $a_{1}$ & $b_{1}$ & $a_{2}$ & $\mathbf{b}_{2}$ & $\lambda_{1}{ }^{\#}$ & $\lambda_{2}^{\#}$ & $\mu_{1}{ }^{\$}$ & $\mu_{2}{ }^{s}$ & $\mathbf{L}_{1}$ & $\mathbf{L}_{2}$ & $\mathbf{L}_{\mathrm{N}}$ & Thp $_{1}$ & $\mathbf{W}\left(\mathbf{N}_{1}\right)$ & Thp $_{2}$ & $\mathbf{W}\left(\mathbf{N}_{2}\right)$ \\
\hline 0.05 & 1 & 6 & 5 & 10 & 5 & 2 & 5 & 20 & 0.77420 & 0.54779 & 1.32198 & 1.08385 & 0.71430 & 2.98333 & 0.18362 \\
\hline 0.1 & 1 & 6 & 5 & 10 & 5 & 2 & 5 & 20 & 1.37714 & 0.85535 & 2.23249 & 1.89133 & 0.72814 & 5.87922 & 0.14549 \\
\hline 0.2 & 1 & 6 & 5 & 10 & 5 & 2 & 5 & 20 & 2.21242 & 1.18741 & 3.39983 & 2.93271 & 0.75440 & 9.14362 & 0.12986 \\
\hline 0.3 & 1 & 6 & 5 & 10 & 5 & 2 & 5 & 20 & 2.71904 & 1.36355 & 4.08259 & 3.49859 & 0.77718 & 10.67417 & 0.12774 \\
\hline 0.4 & 1 & 6 & 5 & 10 & 5 & 2 & 5 & 20 & 3.02633 & 1.46696 & 4.49328 & 3.80769 & 0.79479 & 11.51019 & 0.12745 \\
\hline 1 & 1 & 6 & 5 & 10 & 1 & 2 & 5 & 20 & 0.69528 & 0.92343 & 1.61871 & 1.53587 & 0.45270 & 6.73968 & 0.13701 \\
\hline 1 & 2 & 6 & 5 & 10 & 1 & 2 & 5 & 20 & 0.79461 & 0.94820 & 1.74281 & 1.65055 & 0.48142 & 6.99715 & 0.13551 \\
\hline 1 & 3 & 6 & 5 & 10 & 1 & 2 & 5 & 20 & 0.89394 & 0.97298 & 1.86691 & 1.73597 & 0.51495 & 7.23260 & 0.13453 \\
\hline 1 & 4 & 6 & 5 & 10 & 1 & 2 & 5 & 20 & 0.99326 & 0.99975 & 1.99102 & 1.80469 & 0.55038 & 7.44865 & 0.13395 \\
\hline 1 & 5 & 6 & 5 & 10 & 1 & 2 & 5 & 20 & 1.09259 & 1.02253 & 2.11512 & 1.86239 & 0.58666 & 7.64753 & 0.13371 \\
\hline 1 & 1 & 6 & 5 & 10 & 1 & 2 & 10 & 20 & 0.34998 & 0.92498 & 1.27497 & 1.69575 & 0.20639 & 6.57081 & 0.14077 \\
\hline 1 & 1 & 7 & 5 & 10 & 1 & 2 & 10 & 20 & 0.39998 & 0.94998 & 1.34996 & 1.78241 & 0.2244 & 6.73746 & 0.14100 \\
\hline 1 & 1 & 8 & 5 & 10 & 1 & 2 & 10 & 20 & 0.44998 & 0.97498 & 1.42496 & 1.85954 & 0.24198 & 6.88831 & 0.14154 \\
\hline 1 & 1 & 9 & 5 & 10 & 1 & 2 & 10 & 20 & 0.49998 & 0.99998 & 1.49995 & 1.92900 & 0.25919 & 7.02558 & 0.14233 \\
\hline 1 & 1 & 10 & 5 & 10 & 1 & 2 & 10 & 20 & 0.54998 & 1.02498 & 1.57495 & 1.99214 & 0.27607 & 7.15113 & 0.14333 \\
\hline 1 & 1 & 6 & 1 & 10 & 1 & 2 & 10 & 20 & 0.34998 & 0.72498 & 1.07497 & 1.69575 & 0.20639 & 6.00625 & 0.12070 \\
\hline 1 & 1 & 6 & 2 & 10 & 1 & 2 & 10 & 20 & 0.34998 & 0.77498 & 1.12497 & 1.69575 & 0.20639 & 6.19495 & 0.12510 \\
\hline 1 & 1 & 6 & 3 & 10 & 1 & 2 & 10 & 20 & 0.34998 & 0.82498 & 1.17497 & 1.69575 & 0.20639 & 6.34215 & 0.13008 \\
\hline 1 & 1 & 6 & 4 & 10 & 1 & 2 & 10 & 20 & 0.34998 & 0.87498 & 1.22497 & 1.69575 & 0.20639 & 6.46481 & 0.13535 \\
\hline 1 & 1 & 6 & 5 & 10 & 1 & 2 & 10 & 20 & 0.34998 & 0.92498 & 1.27497 & 1.69575 & 0.20639 & 6.57081 & 0.14077 \\
\hline 1 & 1 & 6 & 5 & 6 & 1 & 2 & 10 & 20 & 0.34998 & 0.72498 & 1.07497 & 1.69575 & 0.20639 & 6.20742 & 0.11679 \\
\hline 1 & 1 & 6 & 5 & 7 & 1 & 2 & 10 & 20 & 0.34998 & 0.77498 & 1.12497 & 1.69575 & 0.20639 & 6.31102 & 0.12280 \\
\hline 1 & 1 & 6 & 5 & 8 & 1 & 2 & 10 & 20 & 0.34998 & 0.82498 & 1.17497 & 1.69575 & 0.20639 & 6.40508 & 0.12880 \\
\hline 1 & 1 & 6 & 5 & 9 & 1 & 2 & 10 & 20 & 0.34998 & 0.87498 & 1.22497 & 1.69575 & 0.20639 & 6.49126 & 0.13479 \\
\hline
\end{tabular}




\begin{tabular}{|l|l|l|l|l|l|l|l|l|l|l|l|l|l|l|l|}
\hline 1 & 1 & 6 & 5 & $\mathbf{1 0}$ & 1 & 2 & 10 & 20 & 0.34998 & 0.92498 & 1.27497 & 1.69575 & 0.20639 & 6.57081 & 0.14077 \\
\hline 1 & 1 & 6 & 5 & 10 & $\mathbf{0 . 5}$ & 2 & 10 & 20 & 0.17499 & 0.83749 & 1.01248 & 0.88723 & 0.19723 & 5.63351 & 0.14866 \\
1 & 1 & 6 & 5 & 10 & $\mathbf{1 . 0}$ & 2 & 10 & 20 & 0.34998 & 0.92498 & 1.27497 & 1.69575 & 0.20639 & 6.57081 & 0.14077 \\
1 & 1 & 6 & 5 & 10 & $\mathbf{1 . 5}$ & 2 & 10 & 20 & 0.52498 & 1.01248 & 1.53745 & 2.43253 & 0.21581 & 7.44695 & 0.13596 \\
1 & 1 & 6 & 5 & 10 & $\mathbf{2 . 0}$ & 2 & 10 & 20 & 0.69997 & 1.09997 & 1.79994 & 3.10394 & 0.22551 & 8.26593 & 0.13307 \\
1 & 1 & 6 & 5 & 10 & $\mathbf{2 . 5}$ & 2 & 10 & 20 & 0.87496 & 1.18746 & 2.06242 & 3.71578 & 0.23547 & 9.03149 & 0.13148 \\
\hline 1 & 1 & 6 & 5 & 10 & 1 & $\mathbf{0 . 5}$ & 10 & 20 & 0.34998 & 0.36248 & 0.71247 & 1.69575 & 0.20639 & 3.63809 & 0.09964 \\
1 & 1 & 6 & 5 & 10 & 1 & $\mathbf{1 . 0}$ & 10 & 20 & 0.34998 & 0.54998 & 0.89997 & 1.69575 & 0.20639 & 4.68069 & 0.11750 \\
1 & 1 & 6 & 5 & 10 & 1 & $\mathbf{1 . 5}$ & 10 & 20 & 0.34998 & 0.73748 & 1.08747 & 1.69575 & 0.20639 & 5.65685 & 0.13037 \\
1 & 1 & 6 & 5 & 10 & 1 & $\mathbf{2 . 0}$ & 10 & 20 & 0.34998 & 0.92498 & 1.27497 & 1.69575 & 0.20639 & 6.57081 & 0.14077 \\
1 & 1 & 6 & 5 & 10 & 1 & $\mathbf{2 . 5}$ & 10 & 20 & 0.34998 & 1.11248 & 1.46247 & 1.69575 & 0.20639 & 7.42652 & 0.14980 \\
\hline 1 & 1 & 6 & 5 & 10 & 1 & 2 & $\mathbf{1 0}$ & 20 & 0.34998 & 0.92498 & 1.27497 & 1.69575 & 0.20639 & 6.57081 & 0.14077 \\
1 & 1 & 6 & 5 & 10 & 1 & 2 & $\mathbf{1 1}$ & 20 & 0.31818 & 0.92499 & 1.24317 & 1.70979 & 0.18609 & 6.54273 & 0.14138 \\
1 & 1 & 6 & 5 & 10 & 1 & 2 & $\mathbf{1 2}$ & 20 & 0.29166 & 0.92500 & 1.21666 & 1.72157 & 0.16942 & 6.51691 & 0.14194 \\
1 & 1 & 6 & 5 & 10 & 1 & 2 & $\mathbf{1 3}$ & 20 & 0.26923 & 0.92500 & 1.94230 & 1.73161 & 0.15548 & 6.49314 & 0.14246 \\
1 & 1 & 6 & 5 & 10 & 1 & 2 & $\mathbf{1 4}$ & 20 & 0.25000 & 0.92500 & 1.17500 & 1.74028 & 0.14366 & 6.47120 & 0.14294 \\
\hline 1 & 1 & 6 & 5 & 10 & 1 & 2 & 10 & $\mathbf{1 6}$ & 0.34998 & 1.15622 & 1.50621 & 1.69575 & 0.20639 & 6.21484 & 0.18604 \\
1 & 1 & 6 & 5 & 10 & 1 & 2 & 10 & $\mathbf{1 7}$ & 0.34998 & 1.08821 & 1.43820 & 1.69575 & 0.20639 & 6.31500 & 0.17232 \\
1 & 1 & 6 & 5 & 10 & 1 & 2 & 10 & $\mathbf{1 8}$ & 0.34998 & 1.02776 & 1.37774 & 1.69575 & 0.20639 & 6.40708 & 0.16041 \\
1 & 1 & 6 & 5 & 10 & 1 & 2 & 10 & $\mathbf{1 9}$ & 0.34998 & 0.97367 & 1.32365 & 1.69575 & 0.20639 & 6.49207 & 0.14998 \\
1 & 1 & 6 & 5 & 10 & 1 & 2 & 10 & $\mathbf{2 0}$ & 0.34998 & 0.92498 & 1.27497 & 1.69575 & 0.20639 & 6.57081 & 0.14077 \\
\hline
\end{tabular}

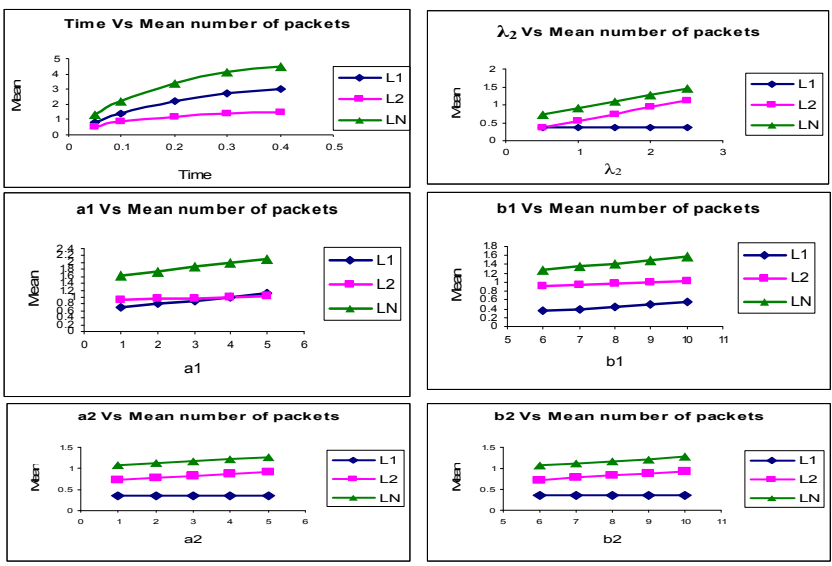

Figure 2. Mean number of packets Vs input parameters

From the equations (36), (37), (44), (45) and (51), mean number of packets of the network are computed for different values of $t$, $a_{1}, b_{1}, a_{2}, b_{2}, \lambda_{1}, \lambda_{2}, \mu_{1}$, and $\mu_{2}$ and are given in Table 1 . The relationship between mean number of packets in the buffers and the parameters $t, a_{1}, b_{1}, a_{2}, b_{2}$, and $\lambda_{2}$ is shown in Figure 2 .
Along with the mean, utilization of the nodes are also computed. It is observed that when time $t$, the batch distribution parameters $a_{1}, b_{1}$ and the message arrival rate $\lambda_{1}$ at node 1 increase, mean number of packets in the first buffer, second buffer and the network and the utilization of both the nodes increase for fixed values of other parameters. When the batch distribution parameters $a_{2}, b_{2}$ and the message arrival rate $\lambda_{2}$ at node 2 increase, the utilization of the second node and mean number of packets in the second buffer and the network increase while the other parameters remain fixed.

When the transmission rate of node $1\left(\mu_{1}\right)$ increases, the mean number of packets in the first buffer and the utilization of the first node decreases where as the mean number of packets in the second buffer increases. When the transmission rate of node $2\left(\mu_{2}\right)$ increases, the mean number of packets in the first buffer remains unchanged and the mean number of packets in the second buffer and the utilization of the second node decreases for fixed values of the other parameters.

From the equations (38), (39), (46) and (47), the throughput and average delay of the network are computed for different values of $\mathrm{t}, \mathrm{a}_{1}, \mathrm{~b}_{1}, \mathrm{a}_{2}, \mathrm{~b}_{2}, \lambda_{1}, \lambda_{2}, \mu_{1}$, and $\mu_{2}$ are given in Table 1 . The relationship between throughput, average delay and parameters is shown in Figure 3 and Figure 4. 


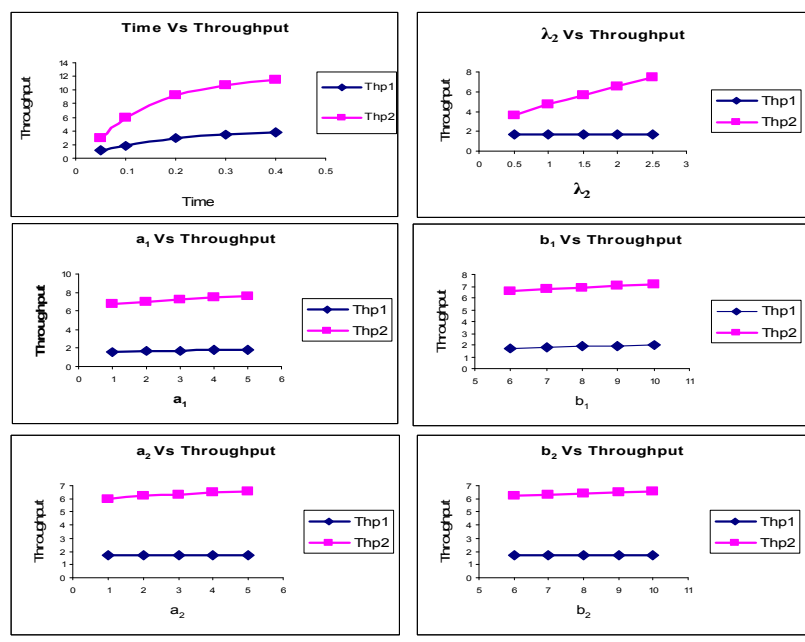

Figure3. Throughput Vs input parameters

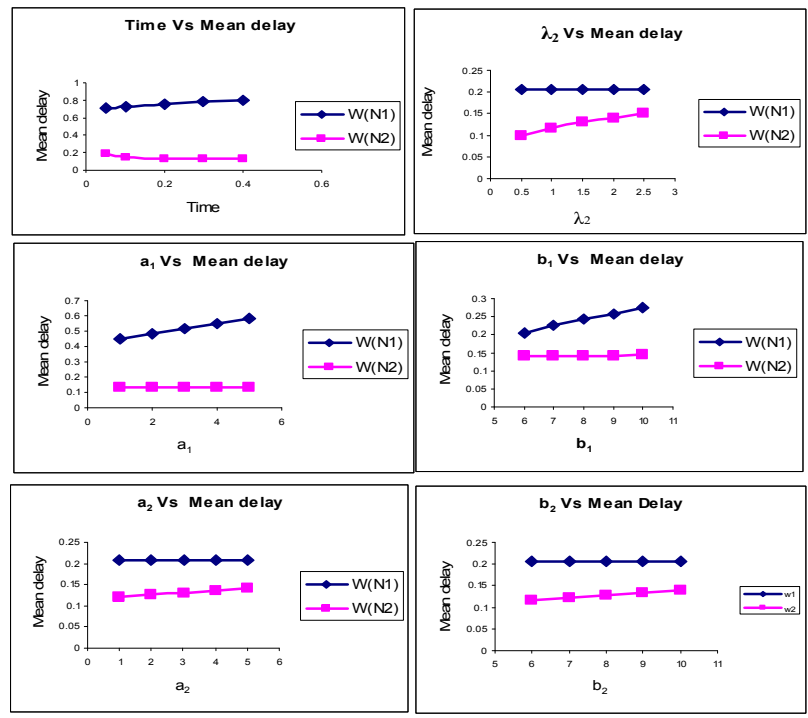

Figure4. Mean delay Vs input parameters

It is observed that as the time $t$, the batch size distribution parameters $a_{1}, b_{1}$ and the message arrival rate $\lambda_{1}$ at node 1 increase, the throughput of the first and second nodes increase and the mean delays varies accordingly in both buffers for fixed values of the other parameters. There is no change in the throughput of the first node and mean delay in the first buffer when the batch size distribution parameters $a_{2}$ and $b_{2}$ increase. Where as, the throughput of the second node and mean delay in the second buffer increase when the values of the other parameters remain fixed. Similarly, the influence of transmission rates of node 1 and node 2 on the throughput of the two nodes and average delay in the buffers can be observed from the table1.

The variance of the number of packets in each buffer, the coefficient of variation of the number of packets in first and second buffers are computed and analyzed.

If the variance increases, then the burstness of the buffers will be high. Hence, the parameters are to be adjusted such that the variance of the buffer content in each buffer must be small. The coefficient of variation of the number of packets in each buffer helps us to understand the consistency of the traffic flow through buffers. If coefficient of variation is large then the flow is inconsistent. It also helps us to compare the smooth flow of packets in two or more nodes.

It is observed that, as the time ( $\mathrm{t}$ ) and the batch size distribution parameters $a_{1}$ and $b_{1}$ increase, the variance of the first and second buffers are increasing and the coefficient of variation of the number of packets in the first and second buffers are decreasing. As the batch size distribution parameters $a_{2}$ and $b_{2}$ increase, the variance and coefficient of variation of number of packets in the second buffer are increasing and they remain constant in the first buffer. As the transmission rate of node $1\left(\mu_{1}\right)$ varies from $10 \times 10^{4}$ packets $/ \mathrm{sec}$ to $14 \times 10^{4}$ packets/sec, the variance of the number of packets in first buffer is decreasing and for the second buffer is increasing. The coefficient of variation of number of packets in the first and second buffers is increased. As the transmission rate of node $2\left(\mu_{2}\right)$ varies from $16 \times 10^{4}$ packets/sec to $20 \times 10^{4}$ packets/sec, the variance of the number of packets in the second buffer is decreasing and the coefficient of variation of number of packets in the second buffer is increasing when other parameters remain fixed at $(1,1,6,5,10,1,2,10)$ for $\left(t, a_{1}, b_{1}, a_{2}, b_{2}, \lambda_{1}, \lambda_{2}\right.$, $\left.\mu_{1}\right)$.

From this analysis it is observed that the dynamic bandwidth allocation strategy has a significant influence on all performance measures of the network. It is further observed that the performance measures are highly sensitive towards smaller values of time. Hence, it is optimal to consider dynamic bandwidth allocation and evaluate the performance under transient conditions. It is also to be observed that the congestion in buffers and delays in transmission can be reduced to a minimum level by adopting dynamic bandwidth allocation. This phenomenon has a vital bearing on quality of service (QoS).

\section{SENSITIVITY ANALYSIS}

The sensitivity analysis of the network model is performed with respect to the parameters $t, a_{1}, b_{1}, a_{2}, b_{2}, \lambda_{1}, \lambda_{2}, \mu_{1}$ and $\mu_{2}$ on the mean number packets in the first and second buffers, the mean delays in the first and second buffers and also throughput of the first and second nodes. The following data has been considered for the sensitivity analysis.

$\mathrm{t}=0.1 \mathrm{sec}, \mathrm{a}_{1}=5, \mathrm{a}_{2}=5, \mathrm{~b}_{1}=10, \mathrm{~b}_{2}=10, \lambda_{1}=1 \times 10^{4}$ messages $/ \mathrm{sec}, \lambda_{2}$ $=2 \times 10^{4}$ messages $/ \mathrm{sec} \mu_{1}=10 \times 10^{4}$ packets $/ \mathrm{sec}, \mu_{2}=20 \times 10^{4}$ packets/sec

The performance measures of the model are computed with variation of $-15 \%,-10 \%, 0 \%,+5 \%,+10 \%$ and $+15 \%$ on the input parameters $\mathrm{t}, \lambda_{1}, \lambda_{2}, \mu_{1}, \mu_{2}$ and $-60 \%,-40 \%,-20 \%, 0 \%$, $+20 \%,+40 \%$ and $+60 \%$ on the batch size distribution parameters $a_{1}, b_{1}, a_{2}$ and $b_{2}$ to retain them as integers. The performance measures are highly affected by time (t) and the batch size distribution of arrivals. As (t) increases to $15 \%$, the average number of packets in the two buffers increasing, the average delay in the first buffer is increasing and the average delay in the second buffer is decreasing. Similarly, as arrival rate of messages $(\lambda)$ increases by $15 \%$, the average number of packets in the two buffers increasing, the average delay in the first buffer is increasing and the average delay in the second buffer is decreasing. Overall analysis of the parameters reflects that 
dynamic bandwidth allocation strategy for congestion control tremendously reduces the delays in communication and improves voice quality by reducing burstiness in buffers.

\section{CONCLUSIONS}

This paper deals with the development and analysis of communication network model with dynamic bandwidth allocation (DBA) having direct bulk arrival (BA) to both buffers. The statistical multiplexing is carried with compound Poisson process approximation to the arrival of packets and Poisson process to the transmission completions. The dynamic bandwidth allocation is adapted by instantaneous adjustment of packet service time by utilizing idle bandwidth in the node. The transient analysis of the model is capable of capturing the changes in the performance measures of the network like average content of the buffers, mean delays, throughput of the nodes, idleness of the nodes etc, explicitly. A numerical study reveals that this communication network model is capable of predicting the performance measures more close to the reality. The dynamic bandwidth allocation strategy along with direct bulk arrivals to both buffers can reduce the congestion in buffers and avoid burstness, which improves quality of service more effectively utilizing the idle resource. This network model includes several of the earlier models as particular cases for specific/limiting values of the parameters. It is also possible to extent this communication network model to Non-Markovian service times which require further investigation.

\section{REFERENCES}

[1]. Kleinrock, L. (1976), Queuing Systems, Vol-II : Computer Applications, Wiley publications, New York.

[2]. Sriram, K., and Lucantoni, D.M.(1989), Traffic smoothing effects of bit dropping in a packet voice multiplexer, IEEE Transactions on Communications, Vol.37, No.7, pp 703-712.

[3]. Yukuo Hayashida (1993), Throughput analysis of tandem type go-back NARQ scheme for satellite communications, IEEE Transactions on Communications, Vol.41, pp 15171524.

[4]. Parthasarathy, P.R. and Selvraju, N. (2001), Transient analysis of a Queue where potential customers are discouraged by Queue length. Mathematical Problem in Engineering, Vol.5, No.1, pp 22-42
[5]. Gaujal, B. and Hyon, E.(2002), Optimal routing policies in deterministic queues in tandem, Proceedings of Sixth International Workshop on Discrete Event Systems (WODES'02),pp 251-257.

[6]. Kin K. Leung (2002), Load-dependent service queues with application to congestion control in broadband networks. Performance Evaluation, Vol.50, Issue 1-4, pp 27-40.

[7] Hooi Miin Soo and Jong-Moon Chung (2003), Analysis of Non-preemptive priority queuing of Diffserv Networks with bulk arrivals, International Journal of Electronics \& Communications, Vol.57, No.6, pp.409-414.

[8]. Marcel F.neuts, Jun Guo, Moshe Zukerman and Hai Le Vu (2005), The waiting Time distributions for a TDMA Model with a finite buffer and state dependent service. IEEE Transactions and Communications, Vol.53, No.9, pp 15221532.

[9]. Durresi,A.,Kandkuppa,P., Sridharam,M., Chellapan,S., Barolli,L. and Jain,R.(2006), LED: Load Early Detection: A congestion Control Algorithm based on Router Traffic Load, Journal of Information Processing Society of Japan, Vol.47, No.2, pp 94-107.

[10].P. Suresh Varma and Srinivasa Rao K. (2007), A Communication Network with Load dependent Transmission, International Journal of Mathematical Science, Vol.6, No.2, pp 199-210.

[11].Emre Yetginer and Ezhan Karasam (2008), Dynamic wavelength allocation in IP/WDM metro access networks, IEEE Journal on selected areas in communications, Vol.26, No.3, pp 13-27.

[12]. Stanislav Angelov, Sanjeev Khanna and Keshav Kunal (2009), The network as a storage device: Dynamic routing with bounded buffers, Algorithmica, Vol.55, No.1, pp 71-94.

[13]. Kuda.Nageswara Rao et al. (2010), A Tandem Communication Network with Dynamic Bandwidth Allocation and Modified Phase Type Transmission having Bulk Arrivals, International journal of computer science issues, Vol.7, No.3, pp.18-26.

[14].Anyne Chen - Phil pollett - jumping Li-Hanjun Zhang (2010), Markovian Bulk arrivals and bulk-service queues with state-dependent control, queuing systems Vol.64, pp.267-304. 